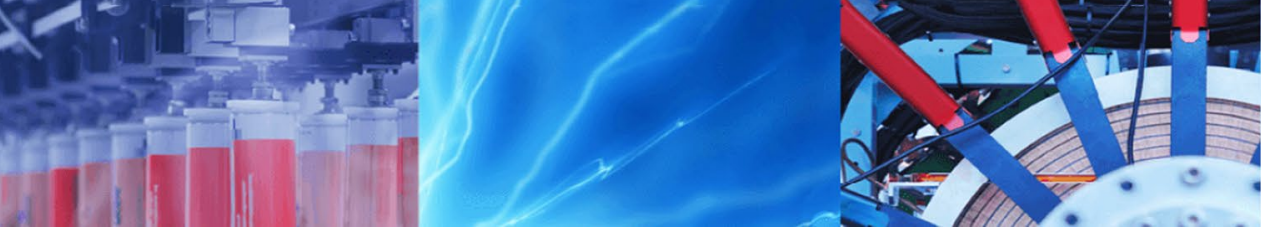

Research Article

\title{
The effect of packing phase and mold temperature on the directional warpage of spherical lenses using the injection molding process
}

\author{
H. Barghikar ${ }^{1} \cdot$ P. Mosaddegh ${ }^{1}$ (D) M. Masoumi ${ }^{2} \cdot$ M. Ranjbar ${ }^{3}$
}

(c) Springer Nature Switzerland AG 2019

\begin{abstract}
This study investigated the directional warpage on bi-convex and bi-concave spherical lenses by experimentally monitoring the changes in the pressure and temperature of mold cavity and comparing them with the simulation results. Warpage was investigated in the direction of the introduction of molten materials into the cavity of the mold, and when it was perpendicular to the direction of the fluid wave front. Packing conditions, including packing time and packing pressure, and mold temperatures are among the important factors influencing lens warpage and their geometric quality. In this research, these factors were investigated in a full factorial design of experiment. Also, simulation results are in good agreement with the experimental results obtained by the vision measuring machine apparatus. According to the results of this study, the least warpage values in bi-convex and bi-concave lenses in the direction of the fluid wave front were 180 and 200 microns, respectively; while these values were 172 and 198 microns when the lenses were perpendicular to the fluid wave front. The experimental values of these in the direction of the melt in the entrance of the mold for bi-convex and bi-concave lenses were 149 and 186 microns, respectively, while these values were 143 and 180 microns when the lenses were perpendicular to the flow front direction. In addition, the results of the pressure diagram inside the mold cavities indicated the correlation with the warpage, such that when the slope of the pressure graph was lower, the lens warpage was less too.
\end{abstract}

Keywords Warpage $\cdot$ Polymeric lens $\cdot$ Injection molding $\cdot$ Packing pressure $\cdot$ Mold cavity

\section{Introduction}

The injection molding process is very important for the mass production of polymeric lenses due to the high production rate and the low cost of the final products. The application of these lenses is obvious in optoelectronic devices such as mobile phones, tablets, and so on. There is, however, a complex relationship between the injection parameters and the quality of molded plastic spherical lenses in the injection molding process [1-3]. So, characteristics such as warpage, shrinkage, residual stress and birefringence need to be addressed. So far, various factors influencing injection molding parameters have been considered, such as injection velocity, melt temperature, mold temperature, packing pressure and cooling time, to get the optimum geometric quality of polymeric lenses $[2$, 4-6]. Lu and Khim [7], studied the warpage of meniscus concave lens, finding an optimal level of injection parameters to improve the geometric quality with 3 factors of injection parameters; these included injection velocity, packing pressure and mold temperature at 2 different levels, according to the research carried out in this field. According to the results, the mold temperature could be regarded as the most important parameter affecting the

P. Mosaddegh, mosadegh@cc.iut.ac.ir; H. Barghikar, h.barghikar@me.iut.ac.ir; M. Masoumi, mmasoumi@cc.iut.ac.ir; M. Ranjbar, ranjbar@ cc.iut.ac.ir | ${ }^{1}$ Department of Mechanical Engineering, Isfahan University of Technology, Isfahan 8415683111 , Iran. ${ }^{2}$ Department of Chemical Engineering, Isfahan University of Technology, Isfahan 8415683111 , Iran. ${ }^{3}$ Department of Physics, Isfahan University of Technology, Isfahan 8415683111, Iran.

SN Applied Sciences (2019) 1:598 | https://doi.org/10.1007/s42452-019-0615-0

Received: 1 January 2019 / Accepted: 14 May 2019 / Published online: 18 May 2019 
contour error (warpage) of the molded lens. Tsai et al. [8] studied the geometric quality and warpage of a planoconvex lens in order to find the optimal level of parameters with 8 factors in 3 different levels. The results of this study indicated that the most important factor in the warpage of the lenses was packing pressure. Spain et al. [9] also investigated the warpage of a plano-convex lens and a bi-convex lens with the changes in the injection parameters, and the peak to valley (PV) level was measured; finally, a model for improving the quality of lens production was presented. The results of this research showed that the most important factors affecting the total warpage were packing pressure and packing time. Tsai et al. [10] also studied the warpage of a plano-convex lens and investigated the pressure profile in the mold cavity. The results of this study showed that the melt and mold temperature and packing time were the most important parameters influencing the warpage and the accuracy of lenses. Mosaddegh et al. investigated the geometric and optical quality of a bi-convex lens produced by the injection molding process. According to their results, the factors simultaneously affecting the geometric quality and the optical quality of these types of lenses were the melt temperature, packing time, injection pressure and packing pressure, respectively. These factors indicated that the simultaneous control of the pressure, in the mold cavity, both during the injection and at the packing stage, could be the solution for suitable injection with the minimal optical errors [11].

Warpage is due to the different volumetric shrinkage along the piece. In fact, the warpage in the piece can be due to the differential effects or area shrinkage and directional effects. Shrinkage changes from one region to another, which is because of the difference in the cooling rate of the piece, refer to the differential shrinkage. Differential shrinkage arises from the calculation of volumetric shrinkage in the entire lens, resulting in the total warpage [12-15].

As it is known, several parameters play a role in determining the geometric quality of the lenses, especially their warpage. Among them, the packing phase has the greatest effect. The mold temperature is also considered a priority due to the direct impact of the polymer melt. Therefore, this research focused on these factors. The directional effects are due to the variations in the volumetric shrinkage along the molten flow and in a direction perpendicular to it, which can be parallel or perpendicular to the flow of materials. What has been studied in this research is the existence of these directional effects on the lens warpage; in fact, the less the directional warpage and the closer its magnitudes to each other, the better the geometric quality of the lens; also, the dimensional tolerances for installing in the optic systems are better. A careful study of the
Table 1 Factors and levels used in the experiments

\begin{tabular}{lcc}
\hline Factors & Level 1 & Level 2 \\
\hline Mold temperature $\left({ }^{\circ} \mathrm{C}\right)$ & 80 & 90 \\
Packing pressure $(\mathrm{MPa})$ & 90 & 100 \\
Packing time $(\mathrm{s})$ & 8 & 12 \\
\hline
\end{tabular}

Table 2 Values for other injection parameters

\begin{tabular}{ll}
\hline Melt temperature $\left({ }^{\circ} \mathrm{C}\right)$ & 230 \\
\hline Injection pressure $(\mathrm{MPa})$ & 90 \\
Injection time (s) & 6.5 \\
Cooling time (s) & 100 \\
\hline
\end{tabular}

directional effects of warpage can improve the geometric quality of polymer lenses and dimensional tolerances, especially in the injection molding process.

\section{Methodology}

Various factors contribute to the formation of warpage in the polymer lenses. 2 factors of packing (holding) pressure, including packing time (packing conditions in the injection molding) and mold temperatures have the greatest impact on the overall complexity of the lenses. Of course, parameters such as the melting temperature of the polymer also play a role in this regard. The main focus of this study was, therefore, to examine the injection conditions in the packing phase. With several experiments, a 2 level process window was developed for these 3 factors, based on Table 1. Other injection parameters including the injection pressure, the injection time and the constant cooling time were fixed and considered based on Table 2. To investigate the effect of these three parameters, the full factorial method with $8(2 \wedge 3)$ tests was designed.

The basis for selecting levels was a large number of experiments. The filling of the cavities should be consonant, without any air trap or weld lines in the molded lenses. For example, the packing time was chosen in such a way that, firstly, the cavities would be $100 \%$ filled; second, the molten gate of the polymer could be blocked to the mold cavity. Also, according to the initial analysis results, it took about $100 \mathrm{~s}$ for $100 \%$ of the layers to freeze and reach the glass transition temperature, which was the basis for choosing the cooling level. The temperature range of the mold was chosen in such a way to show an interferometry pattern of lenses surface with a minimum peak to valley (PV) value less than 10 microns. This means that selecting temperatures below $80^{\circ} \mathrm{C}$ and more than $90^{\circ} \mathrm{C}$, according to the injection conditions and the experimental results, 


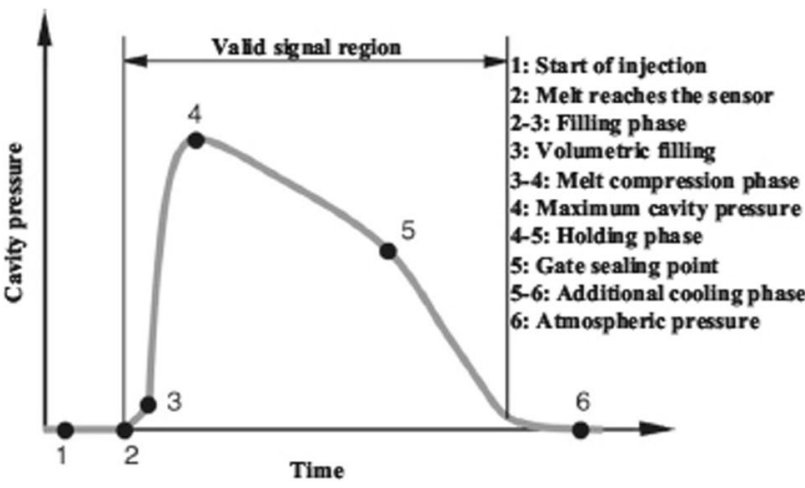

Fig. 1 Determining different injection phases based on a schematic of the trend of mold cavity pressure

will not lead to the desired surface quality of spherical lenses.

The material used in this study was PMMA (Sumipex HT55X) amorphous polymer [16]. Also, the Kistler 6189A temperature-pressure sensor was located in the mold cavity of both lenses. The main application of this sensor was to record the pressure changes during the injection up to the end of the packing time.

Finally, the main objective of this study is to investigate irregular surface by measuring directional warpage, focusing on three main parameters of injection molding for spherical lenses. The lowest directional warpage and its maximum value are discussed with the trend analysis of the pressure diagram inside the mold cavity. Using this method to prevent the high cost of measuring lenses individually can be reliable, From the study of the trend of the molding cavity pressure variations, details of the injection conditions can be found [10]. Figure 1 shows a schematic diagram of the mold cavity pressure.

The molded lenses from the experiments were accurately measured with the vision measuring machine (profile projector); the results were compared with the simulations obtained from the Moldflow Insight software. Then, the least warpage in the direction of flow and that perpendicular to it has been discussed.

\section{Experiments}

These experiments were performed with a 4-cavity mold, as shown in Fig. 2. The pressure sensor was installed in the middle of the lenses, as illustrated in Fig. 3. The cavities of this mold were two by two geometrically identical and opposite of each other. The main parameters of the lenses geometry are presented in Table 3 and Fig. 4.

The injection process parameters were obtained according to the conditions of the tests in Table 4. Figure 5

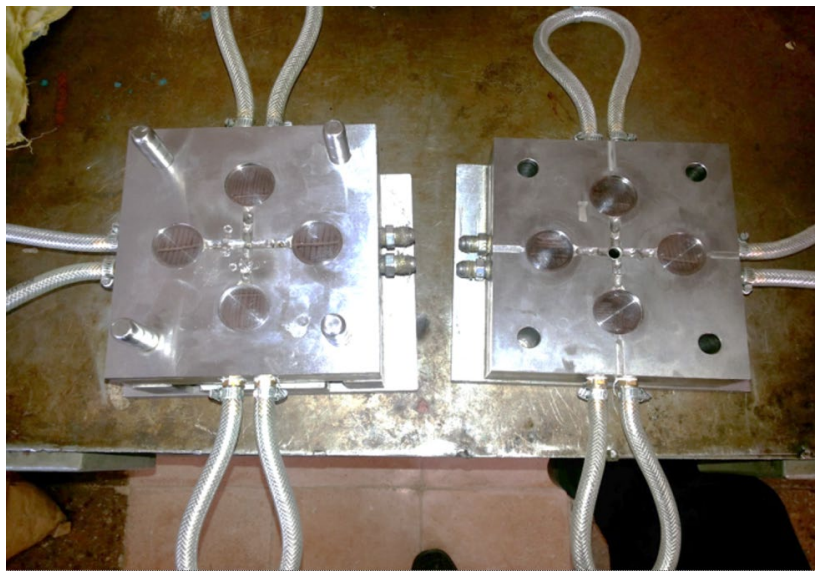

Fig. 2 The 4-cavity mold for injecting bi-convex and bi-concave spherical lenses

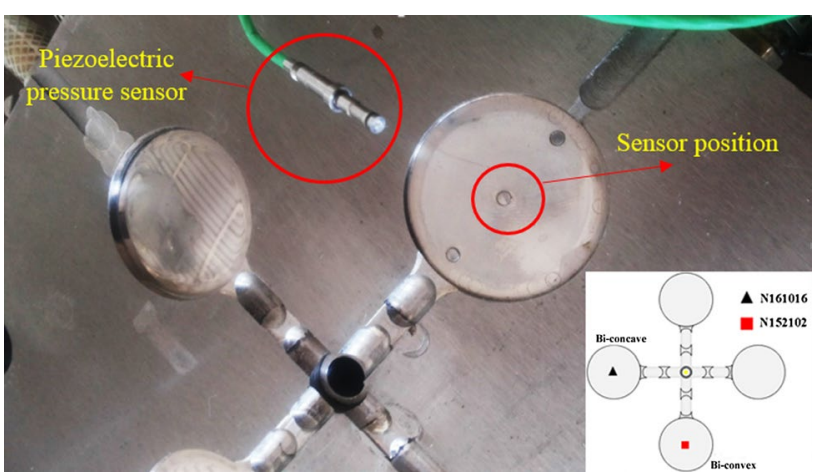

Fig. 3 The position of the sensor in the lens mold cavity

Table 3 The main values of the lens geometry designed for this research

\begin{tabular}{llll}
\hline & $\begin{array}{l}\text { Radius curvature } \\
(\mathrm{mm})\end{array}$ & $\begin{array}{l}\text { Lens thickness } \\
(\mathrm{mm})\end{array}$ & $\begin{array}{l}\text { Lens } \\
\text { diameter } \\
(\mathrm{mm})\end{array}$ \\
\hline Bi-convex & 220 & 4.22 & 36.5 \\
Bi-concave & 220 & 3.98 & 36.5 \\
\hline
\end{tabular}

shows bi-convex and bi-concave molded lenses as well as the desired direction of measurement. The lenses were measured twice, once parallel to the melted polymer flow, and once in a vertical position, by the vision measuring machine. The results of these measurements are presented in Table 5.

Due to the shape of the holes in the mold, the $Y$ axis for the bi-convex lenses was parallel to the material flow and the $\mathrm{X}$ axis was perpendicular to it, while it was opposite for the bi-concave lenses. It is clear from Table 5 that for both lenses, the experiment no. 2 had the highest 


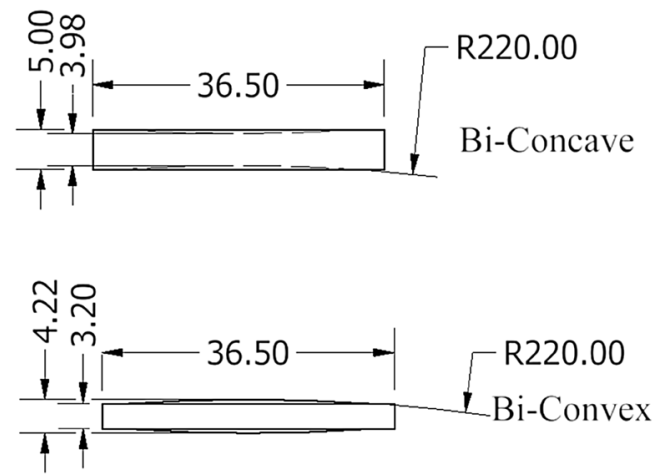

Fig. 4 Geometric dimensions of bi-convex and bi-concave spherical Lenses

directional deviation, while the experiment no. 5 showed the lowest one. The difference between the minimum and maximum dimensional deviation was 26 and 33 microns, respectively, in the bi-convex lens. The difference was between 27 and 30 microns for the bi-concave lens too. This difference in the lens layout in an optical system created the optical aberrations. Comparing the results of the experiment no. 5 , with a mold temperature of $80^{\circ} \mathrm{C}$ and a packing pressure of $100 \mathrm{MPa}$ over a period of $8 \mathrm{~s}$, with the experiment no. 2 , with a mold temperature of $90^{\circ} \mathrm{C}$ and a packing pressure of $90 \mathrm{MPa}$ for $12 \mathrm{~s}$, indicated that an increase in packing time could not necessarily trigger the reduced warpage. Also, the high mold temperature could not help this procedure. Instead, the temperature of the mold should be determined according to the polymer conditions and its properties. It could also be observed that in the case of the least deviations, the values of both directional warpages were close together and the lens had a better fit in line with direction. The difference in this value was 8 microns in the bi-convex lens and 2 microns in the bi-concave one.

Due to the fact that the minimum warpage value is specified in bi-convex and bi-concave lenses, and the

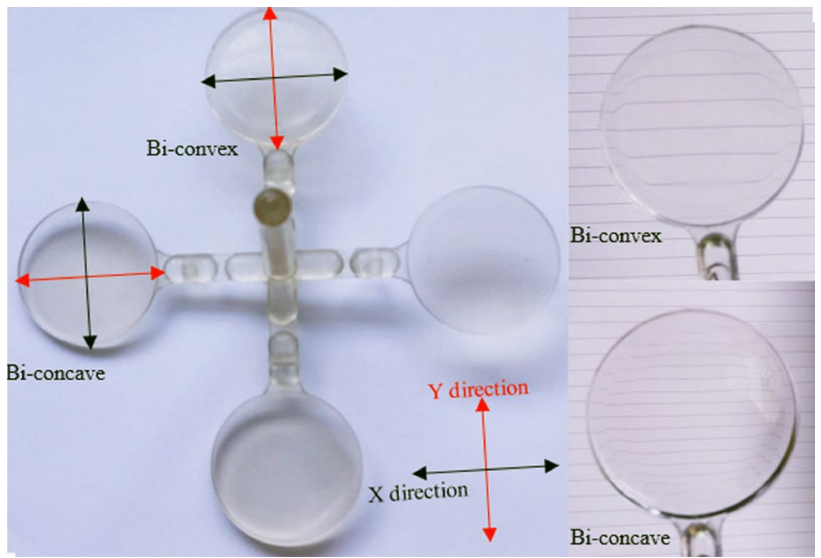

Fig. 5 Injected lenses designed by the 4-cavity mold

test conditions creating it are also specified, tracing the trend of pressure variations in the mold cavity could greatly help the production process [17-19]. Therefore, by placing the piezoelectric pressure sensor (the shape and method of installation can be seen in the experiments section) in the mold cavity, the output values could be recorded. Figures 6 and 7 show two trends in the pressure variations in the mold cavity from the start to the end of injection in both simulation and experimental states. Further, the range of injection phases included filling, packing and cooling stages, as shown in the pressure graphs.

The path that had the circle mark in both simulation and experimental modes represented the minimum warpage. As previously noted, longer packing times could not reduce warpage. In other words, it could be determined that if the pressure in each injection follows the trend of the above diagrams, the lenses may have the least directional warpage. A difference of 5 and $7 \mathrm{~s}$ could be seen in the experimental and simulation trend, depending on the sensor conditions. However, the methods of slope reduction and the maximum pressure
Table 4 Number and conditions of experiments

\begin{tabular}{lllrllll}
\hline & $\begin{array}{l}\text { Melt } \\
\text { tempera- } \\
\text { ture }\end{array}$ & $\begin{array}{l}\text { Packing } \\
\text { pressure }\end{array}$ & Packing time & $\begin{array}{l}\text { Mold } \\
\text { tempera- } \\
\text { ture }\end{array}$ & $\begin{array}{l}\text { Injection } \\
\text { pressure }\end{array}$ & Injection time & Cooling time \\
\hline Exp. No-1 & 230 & 90 & 8 & 80 & 90 & 6.5 & 100 \\
Exp. No-2 & 230 & 90 & 12 & 80 & 90 & 6.5 & 100 \\
Exp. No-3 & 230 & 90 & 8 & 90 & 90 & 6.5 & 100 \\
Exp. No-4 & 230 & 90 & 12 & 90 & 90 & 6.5 & 100 \\
Exp. No-5 & 230 & 100 & 8 & 80 & 90 & 6.5 & 100 \\
Exp. No-6 & 230 & 100 & 12 & 80 & 90 & 6.5 & 100 \\
Exp. No-7 & 230 & 100 & 8 & 90 & 90 & 6.5 & 100 \\
Exp. No-8 & 230 & 100 & 12 & 90 & 90 & 6.5 & 100 \\
\hline
\end{tabular}


Table 5 The results of the dimension measurement of lenses

\begin{tabular}{|c|c|c|c|c|}
\hline & \multicolumn{2}{|l|}{ Bi-convex } & \multicolumn{2}{|l|}{ Bi-concave } \\
\hline & $\begin{array}{l}\text { Dimensional variation in the per- } \\
\text { pendicular material flow }(X)\end{array}$ & $\begin{array}{l}\text { Dimensional variation in the } \\
\text { material flow }(\mathrm{Y})\end{array}$ & $\begin{array}{l}\text { Dimensional variation in the } \\
\text { material flow }(X)\end{array}$ & $\begin{array}{l}\text { Dimensional variation in the } \\
\text { perpendicular material flow }(\mathrm{Y})\end{array}$ \\
\hline 1 & 182 & 195 & 198 & 192 \\
\hline 2 & 198 & 213 & 230 & 225 \\
\hline 3 & 174 & 198 & 217 & 220 \\
\hline 4 & 175 & 205 & 224 & 200 \\
\hline 5 & 172 & 180 & 200 & 198 \\
\hline 6 & 172 & 208 & 221 & 195 \\
\hline 7 & 182 & 195 & 218 & 216 \\
\hline 8 & 162 & 195 & 221 & 215 \\
\hline
\end{tabular}

Fig. 6 The trend of pressure variations from the beginning to the end of the injection process in both simulation and experimental conditions for the bi-convex lens

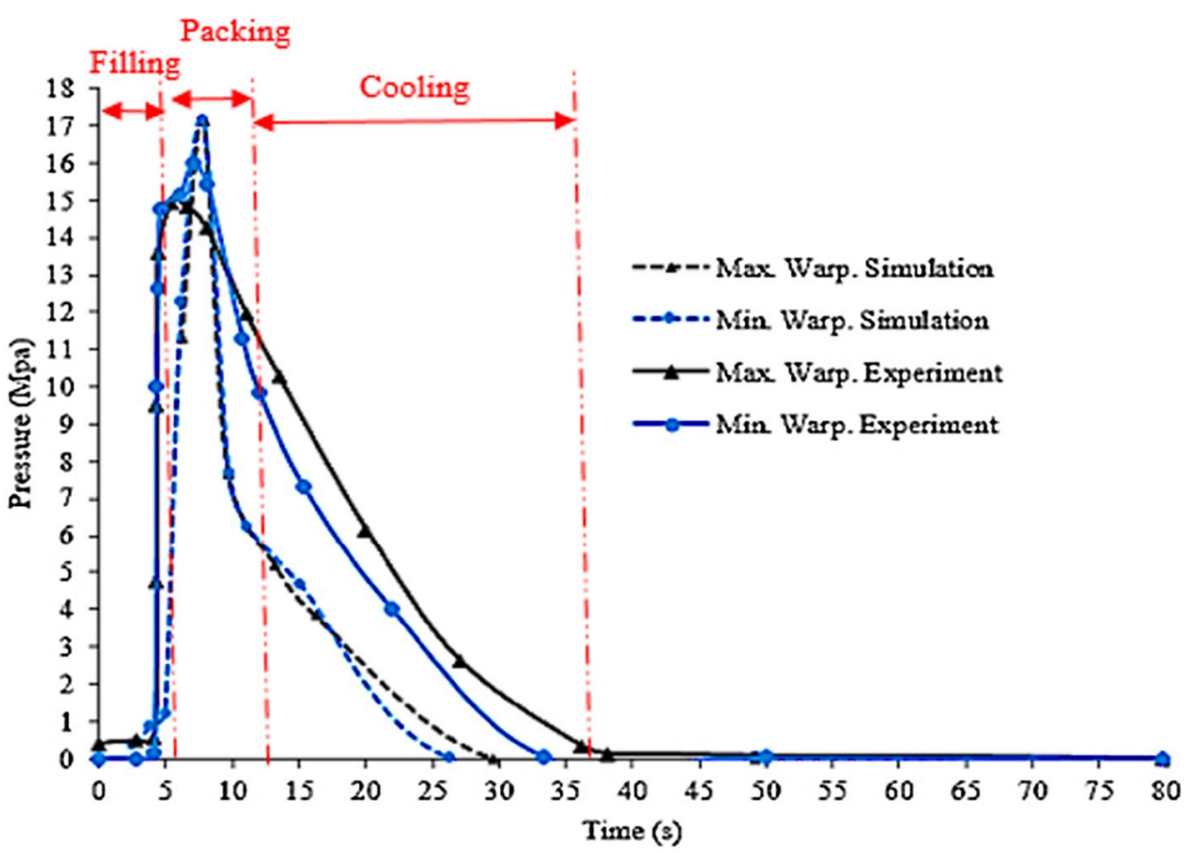

points were consistent with each other. Table 6 shows the important numerical values in tracing the mold cavity pressure.

According to the data in Table 6, the amount of pressure in the mold cavity with the least directional warpage for both lenses was close to each other and is approximately $16 \mathrm{MPa}$. For the bi-convex lens, this pressure was $33 \mathrm{~s}$ until closing the gate and $30 \mathrm{~s}$ for the bi-concave lens.

In this research, the focus was to study the pressure conditions inside the mold cavity and its role in warpage. The simulations also showed the pressure drop in the runner system and the mold cavity. For example, Figs. 8 and 9 show the pressure variations in the bi-concave lens from the runners to the mold cavity. According to the Figs. 8 and 9 , the amount of pressure drop from the first runner to the final gate was such that in the mold cavity, the 65-70\% pressure drop occurred. Changes in packing conditions also cause changes in the pressure diagrams. In other words, changes in the low range during packing pressure will have a huge impact on the directional warpage.

\section{Simulations}

Simulation of the injection molding process was performed using the Moldflow Insight 2016 software. The simulation considered runners, gates, and sprues with a total of 1602279 meshes and a size of $0.75 \mathrm{~mm}$, as shown in Fig. 10.

The directional warpage varied, as depicted in Figs. 11 and 12 , which are related to the test no. 2,with the highest deviation for bi-convex and bi-concave lenses, thereby showing the contour of warpage along the melt flow of 
Fig. 7 The trend of pressure variations from the beginning to the end of the injection process in both simulation and experimental conditions for the bi-concave lens

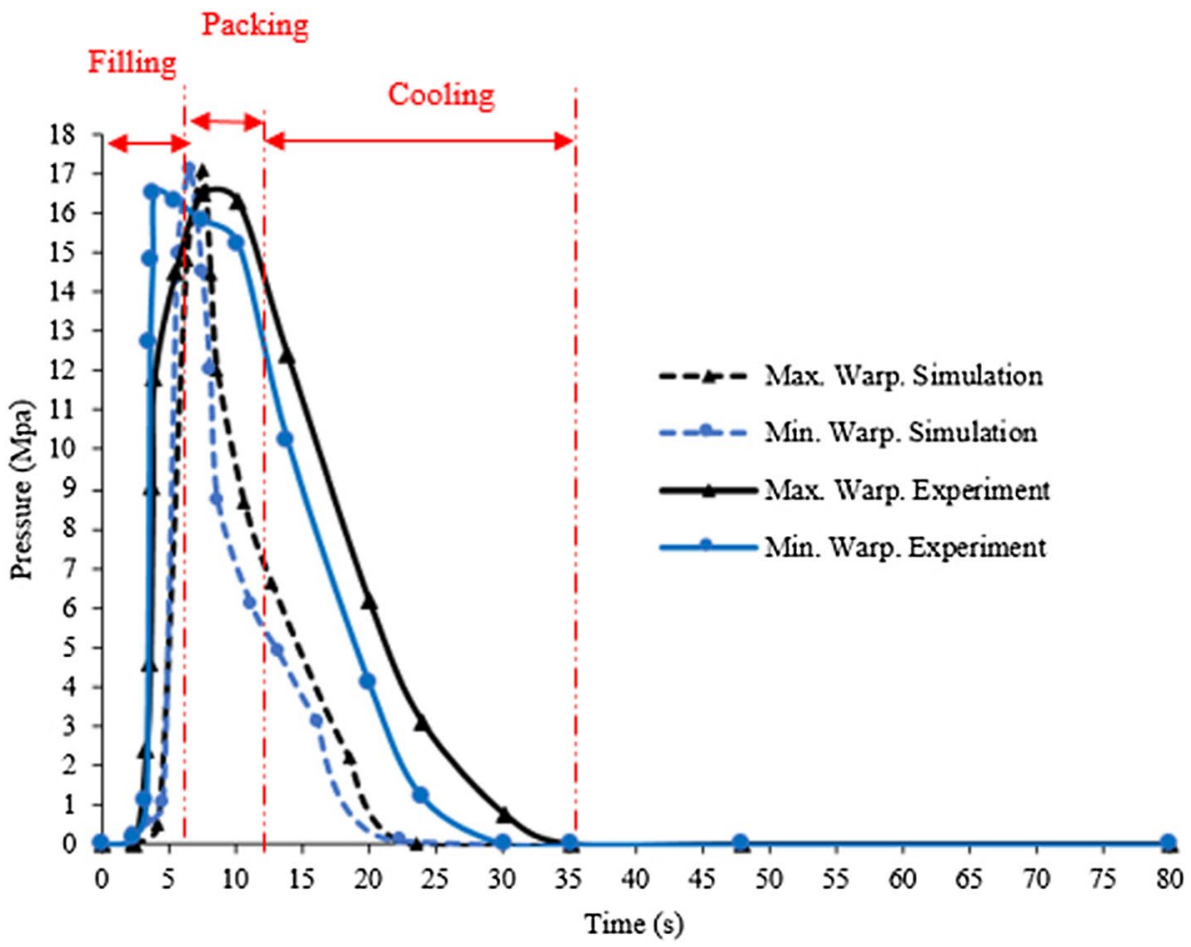

Table 6 The table of maximum pressure and time pressure reaching zero in the experiments

\begin{tabular}{lllll}
\hline & $\begin{array}{l}\text { Maximum } \\
\text { pressure } \\
\text { in the least } \\
\text { warpage } \\
\text { condition }\end{array}$ & $\begin{array}{l}\text { Pressure } \\
\text { zeroing } \\
\text { time in } \\
\text { the least } \\
\text { warpage } \\
\text { condition }\end{array}$ & $\begin{array}{l}\text { Maximum } \\
\text { pressure } \\
\text { in the } \\
\text { maximum } \\
\text { warpage } \\
\text { condition }\end{array}$ & $\begin{array}{l}\text { Pressure } \\
\text { zeroing } \\
\text { time in the } \\
\text { maximum }\end{array}$ \\
$\begin{array}{lllll}\text { warpage } \\
\text { condition }\end{array}$ \\
\hline $\begin{array}{l}\text { Bi-convex } \\
\text { lens }\end{array}$ & 16.1 & 33.2 & 15.2 & 37 \\
$\begin{array}{c}\text { Bi-concave } \\
\text { lens }\end{array}$ & 16.4 & 30.1 & 17.3 & 35.1 \\
\hline
\end{tabular}

the polymer. Also, Figs. 13 and 14 show warpage in the direction of the flow perpendicular to both lenses.

According to Figs. 11 and 12, it is clear that in line with the mold gate and the end of it, the amount of this warpage was at its maximum and minimum in the center of the lenses. This could be related to the amount of the shrinkage of the polymer. According to the simulations in Fig. 15, the greatest amount of shrinkage occurred in the thick areas of the lens, and the polymer melt volume and temperature gradient changes in these regions could result in more shrinkage. Also, the value of the deviation from the nominal size was larger in the direction of the current flow, as compared to the vertical direction. The reason for this was the sudden change in temperature from the gate into the mold cavity. The rheology properties and the PVT graph of the assigned PMMA polymer are shown in Figs. 16 and 17, respectively. These graphs display important information about the polymer's behavior when encountering different temperatures and pressures. Behaviors such as polymer shrinkage play a major role in the directional warpage $[20,21]$. Therefore, it is necessary to add these properties to the software before the simulation runs. Table 7 shows the values obtained from the simulation of the directional warpage of the lens.

As already mentioned, the amount of warpage in a direction perpendicular to the lens plane ( $Z$ axis) is somewhat negligible and almost constant in comparison with other directions. Therefore, it has been ignored in this study. Columns 4 and 7 in Table 7 show the simulated values in the direction of the $Z$ axis.

\section{Discussion}

Figures 18 and 19 are the two charts derived from the output of Tables 5 and 7. Figure 18 shows the directional warpage simulation values for both bi-convex and biconcave lenses. In Fig. 19, the same parameter has been investigated in the experiments.

In this figure, the warpage values aligned perpendicular to the lens plane ( $Z$ axis) show a significant difference from other values, and they are specified and relatively constant. Also, the minimum value of the warpage was specified to show the experiment no. 5. Also, in the experiment no. 2 , the maximum warpage points could be observed. 
Fig. 8 The trend of pressure in the feeding system and mold cavity for bi-concave lenses at maximum warpage
Fig. 9 Investigating the trend of pressure in the feeding system and mold cavity for bi-concave lenses at minimum warpage
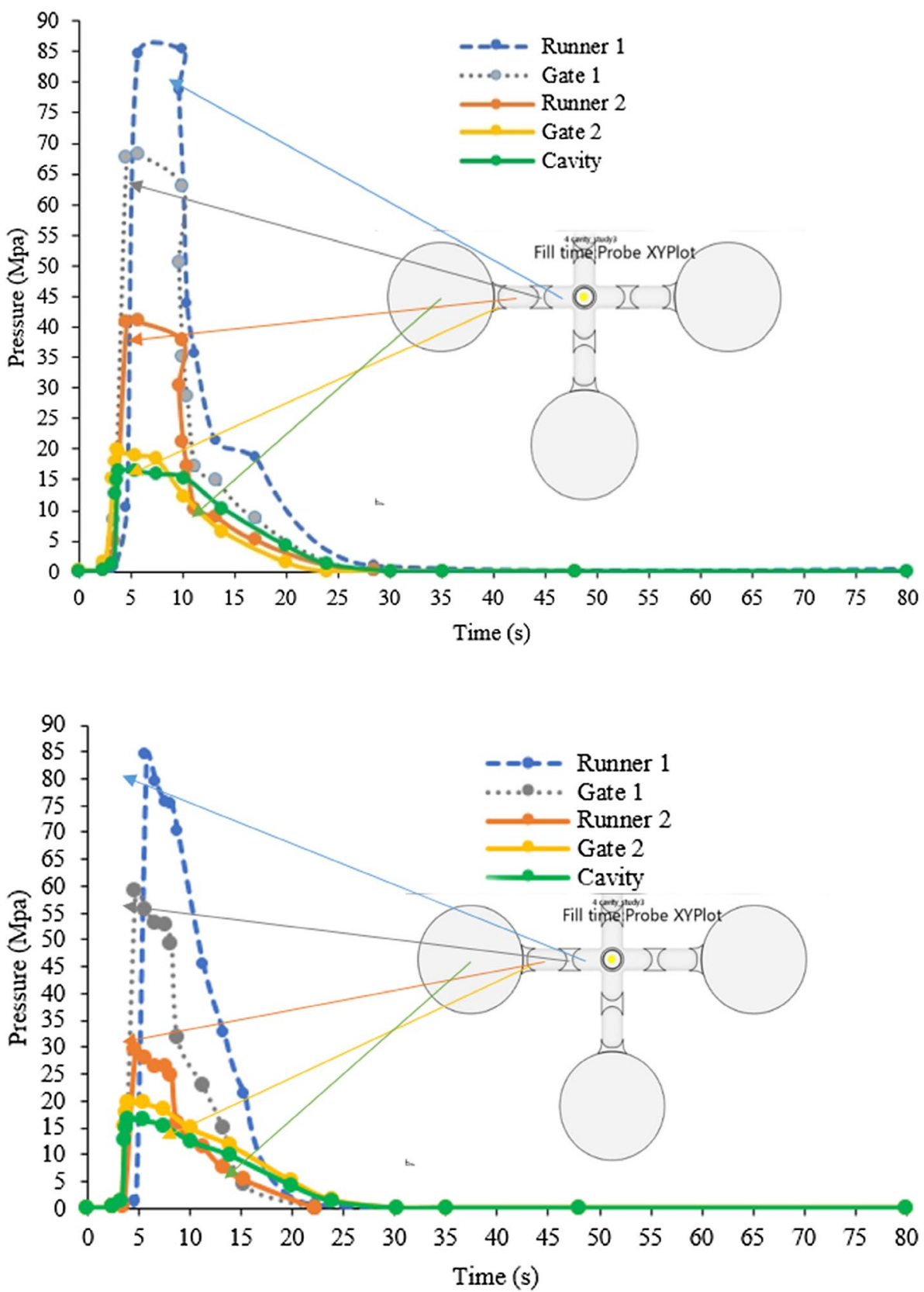

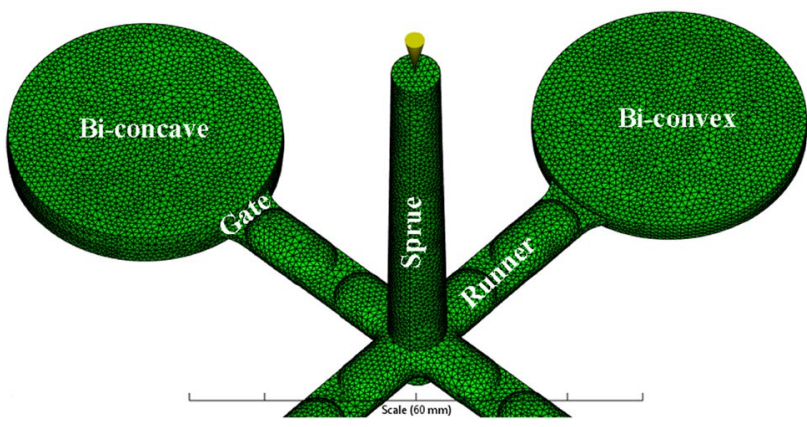

Fig. 10 Meshing the mold cavity and the 4-cavity-mold feeding system
Comparing the 2 charts of Figs. 18 and 19 reveals that the trends of the experiments and simulations diagrams were the same, both confirming each other. This means that experiment no. 5 conditions led to the minimum warpage. It is also clear that the warpage values did not fluctuate in the vertical direction of the flow in the biconcave lens, because the rate of temperature variation in the vertical direction of the flow in the bi-concave lens was not high. Also, the numerical values in the experiment no. 5 conditions for both lenses, in both directions, were close to each other and close to the simulation. 


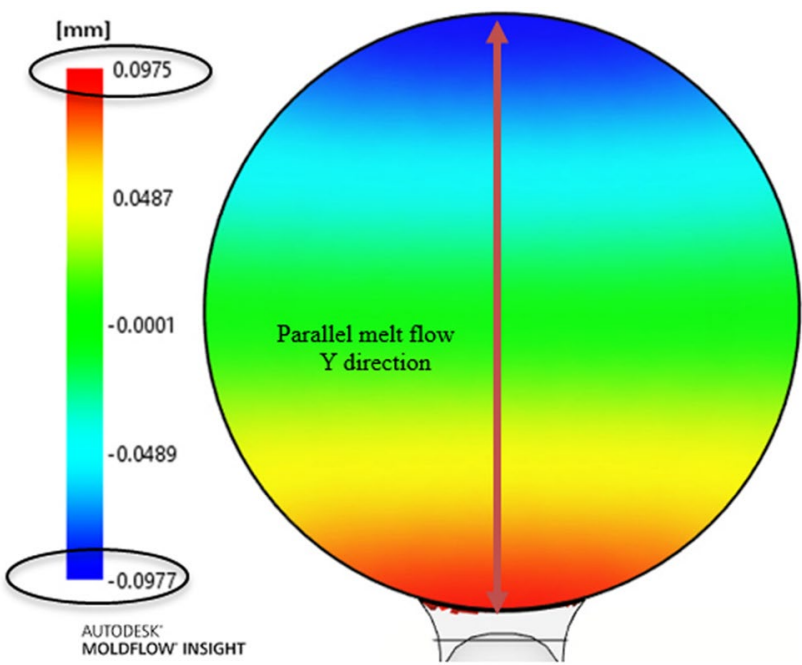

Fig. 11 Warpage of the bi-convex lens in the direction of melt flow-the total deviation of 194 microns

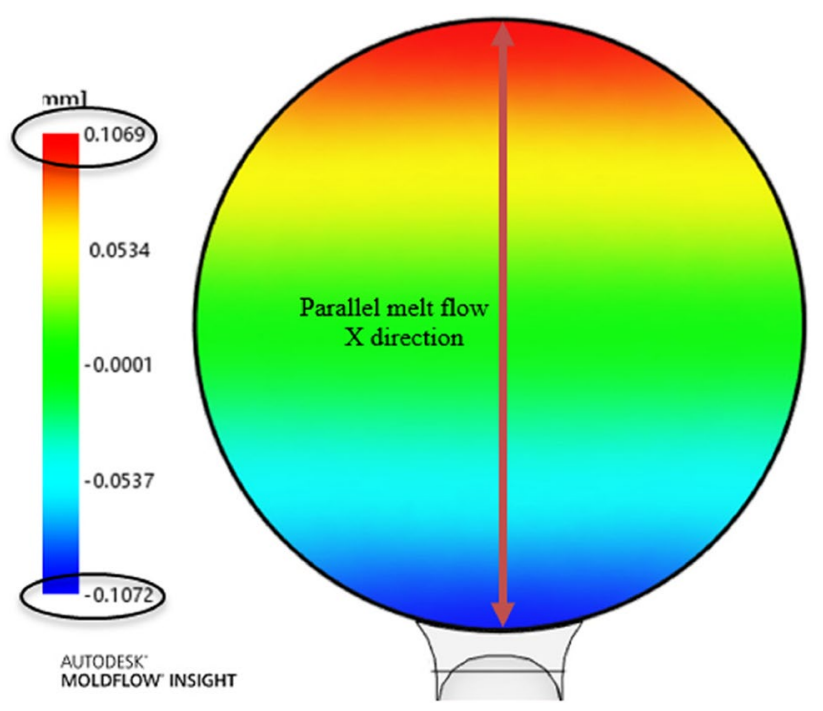

Fig. 12 Warpage of the bi-concave lens in the direction of the melt flow-the total deviation of 213 microns

\section{Conclusions}

1. The conditions in which the lenses exhibited the least warpage, according to the results, consisted of a melting temperature of $230{ }^{\circ} \mathrm{C}$, a mold temperature of $80^{\circ} \mathrm{C}$, and a $90 \mathrm{MPa}$ injection pressure in $6.5 \mathrm{~s}$, with a packing pressure of $100 \mathrm{MPa}$ in $8 \mathrm{~s}$. These data were, therefore, in a good agreement with the simulation results, proving that this methodology could be a good tool to predict the lens warpage. The high temperature of the mold and the increase in the packing

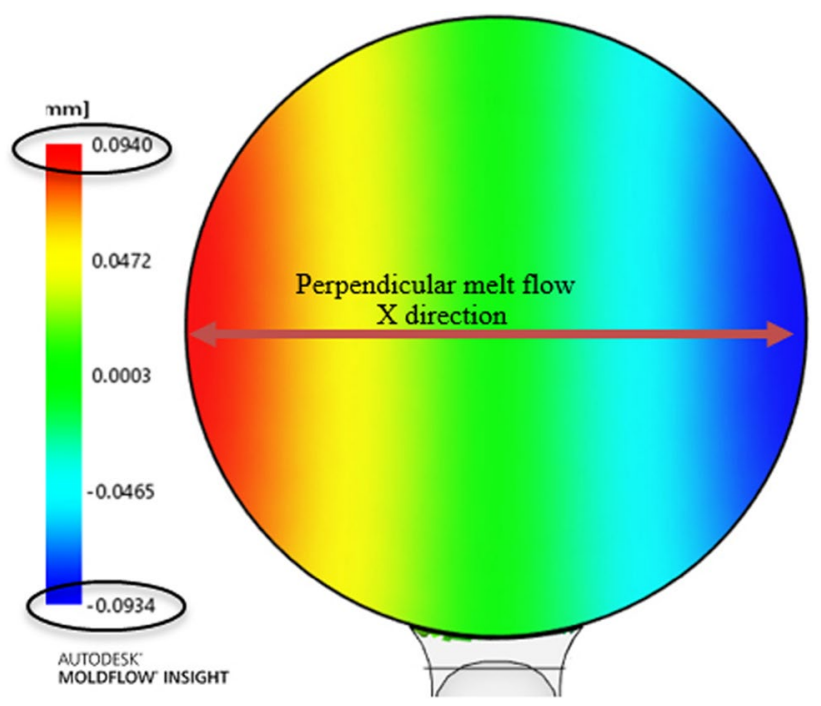

Fig. 13 Warpage of the bi-convex lens perpendicular to the melt flow-the total deviation of 187 microns

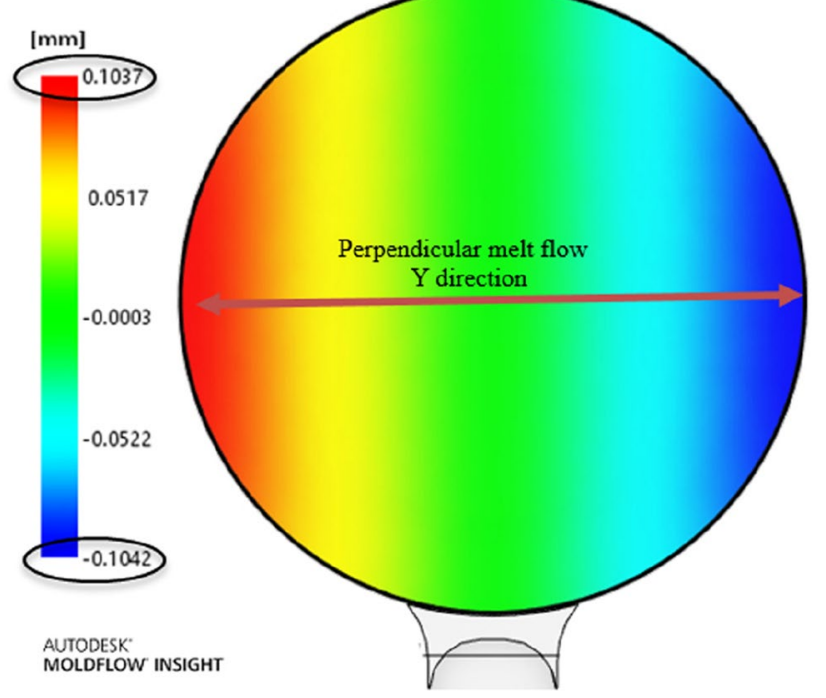

Fig. 14 Warpage of the bi-concave lens perpendicular to the melt flow-the total deviation of 207 microns

time may not reduce the directional warpage and the minimum level could be limited. In the mentioned conditions, the directional warpage of the lens was minimum and in both directions, parallel to the flow direction and perpendicular to it, the values were close to each other. The directional warpage difference was $8 \mu \mathrm{m}$ for the bi-convex lens and $2 \mu \mathrm{m}$ for the bi-concave lens. Due to the important role of the directional warpage in the installation of the continuous optic systems, the pressure has been traced within the mold cavity. 

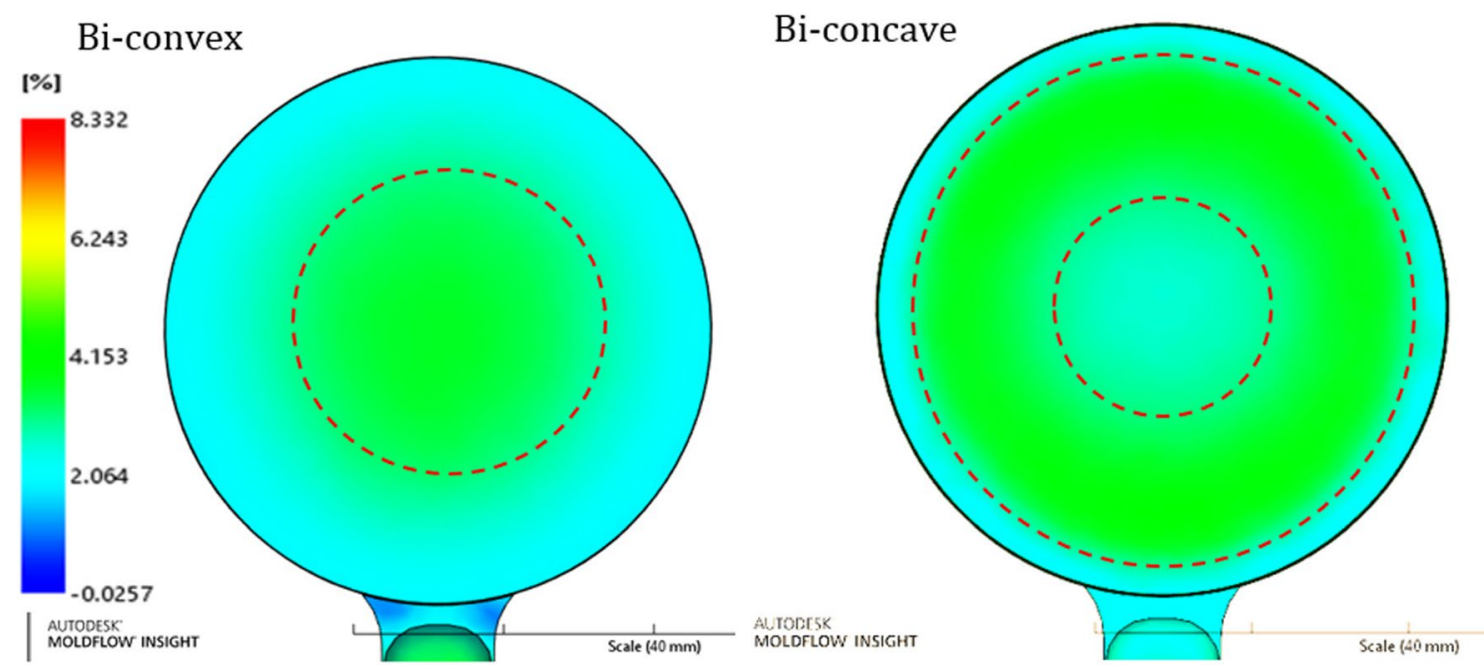

Fig. 15 Lens shrinkage volume after the end of the cooling phase

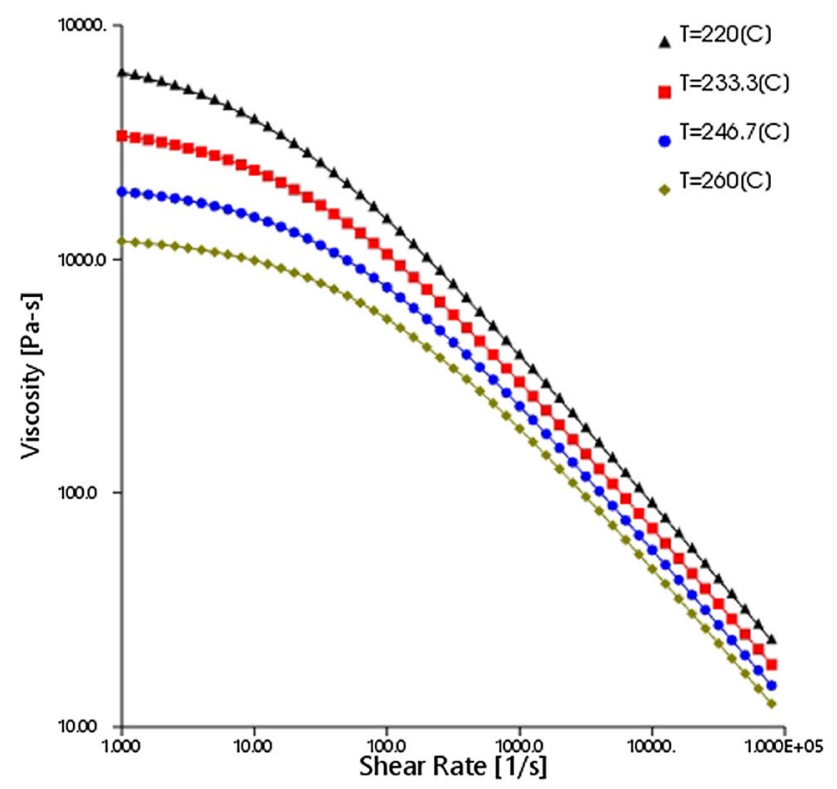

Fig. 16 Viscosity graph versus shear rate at different temperatures

2. The trend diagram of the pressure showed that the increase in the time required to make the pressure caused by packing time reach zero was directly related to the directional warpage. In other words, the direction of diagram in the $X$ axis (the time axis) could be important, such that in the experiments, this difference for the maximum and minimum warpage in the bi-convex lens was $4 \mathrm{~s}$, while for the bi-concave lens, this was $5 \mathrm{~s}$ (lower values could result in the minimal directional warpage).

3. The packing condition, despite the low $10 \mathrm{MPa}$ range, had an intensive effect on the reduction of directional

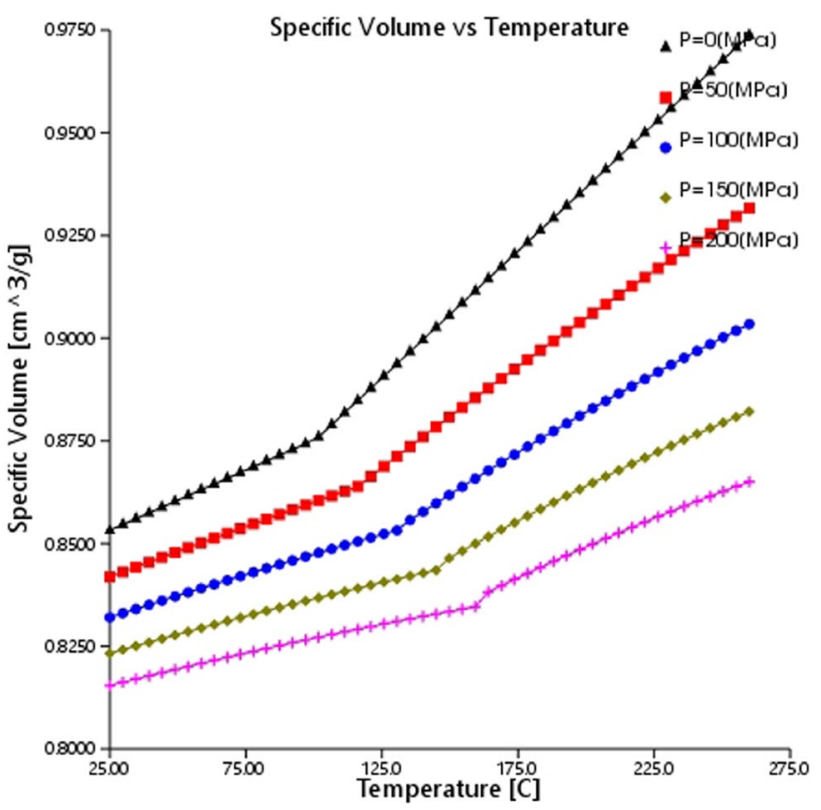

Fig. 17 Polymer behavior properties at different pressures of PVT

warpage, so that with a $10 \%$ change in these conditions, the warpage improved approximately $30 \%$ in the experiments along the $X$ and $Y$ directions for the bi-convex and bi-concave lenses.

4. Injection pressure was different from the mold cavity pressure. The difference between the maximum mold cavity pressure for the most and least amounts of directional warpage in both lenses was about $1 \mathrm{MPa}$. However, for the bi-convex lens, the minimum warpage was $1.1 \mathrm{MPa}$ greater than its maximum, and for the bi-concave lens, it was opposite. So, the minimum amount of warpage was $0.9 \mathrm{MPa}$ less than its maxi- 
Table 7 The warpage values obtained from the simulation of the lenses

\begin{tabular}{|c|c|c|c|c|c|c|}
\hline & \multicolumn{3}{|l|}{ Convex } & \multicolumn{3}{|l|}{ Concave } \\
\hline & $\begin{array}{l}\text { Dimensional variation } \\
\text { in the perpendicular } \\
\text { material flow }(X)\end{array}$ & $\begin{array}{l}\text { Dimensional varia- } \\
\text { tion in the material } \\
\text { flow }(\mathrm{Y})\end{array}$ & $\begin{array}{l}\text { Dimensional } \\
\text { variation in the } Z \\
\text { direction }\end{array}$ & $\begin{array}{l}\text { Dimensional varia- } \\
\text { tion in the material } \\
\text { flow }(X)\end{array}$ & $\begin{array}{l}\text { Dimensional varia- } \\
\text { tion in the perpen- } \\
\text { dicular material flow } \\
\text { (Y) }\end{array}$ & $\begin{array}{l}\text { Dimensional } \\
\text { variation in the Z } \\
\text { direction }\end{array}$ \\
\hline & $x$ & $Y$ & Z & $x$ & $Y$ & Z \\
\hline 1 & 170 & 177 & 24 & 198 & 198 & 26 \\
\hline 2 & 187 & 194 & 24 & 213 & 207 & 31 \\
\hline 3 & 169 & 176 & 24 & 197 & 193 & 28 \\
\hline 4 & 163 & 175 & 22 & 203 & 198 & 29 \\
\hline 5 & 143 & 149 & 20 & 186 & 180 & 26 \\
\hline 6 & 145 & 150 & 21 & 196 & 192 & 28 \\
\hline 7 & 168 & 165 & 22 & 205 & 199 & 30 \\
\hline 8 & 145 & 150 & 20 & 190 & 185 & 26 \\
\hline
\end{tabular}

Fig. 18 Simulated directional warpage values

Fig. 19 Measured warpage values in the experiments
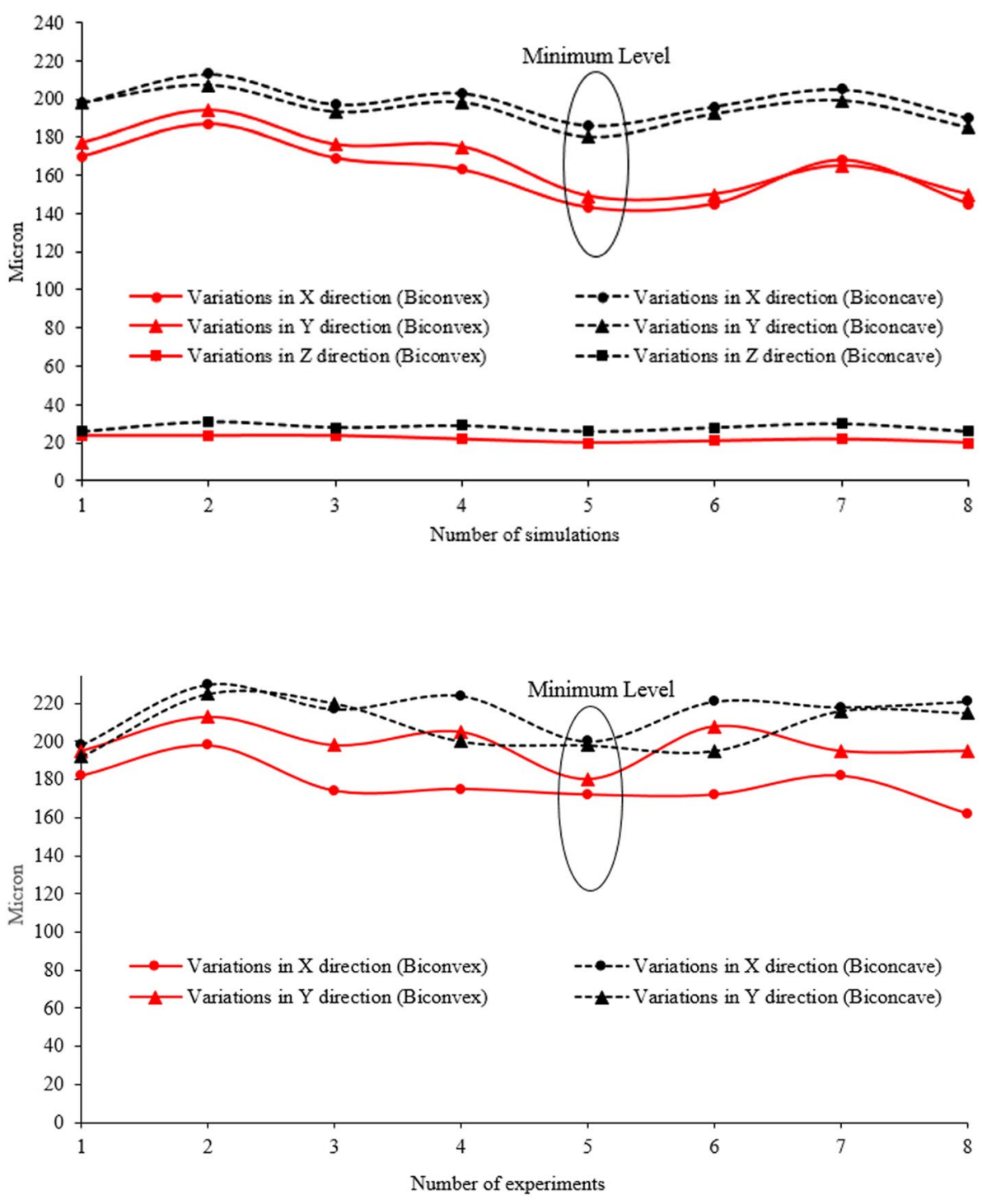
mum. This difference was related to the geometry of the lenses, as the surface curvature was changed in the position of the sensor.

5. The optimum level with the minimum directional warpage consisted of a melting temperature of $230^{\circ} \mathrm{C}$, a mold temperature of $80^{\circ} \mathrm{C}$, and a $90 \mathrm{MPa}$ injection pressure in $6.5 \mathrm{~s}$, with a packing pressure of $100 \mathrm{MPa}$ in $8 \mathrm{~s}$.

\section{Compliance with ethical standards}

Conflict of interest The authors declare that they have no conflict of interest.

\section{References}

1. Sortino $M$, Totis $G$, Kuljanic E (2014) Comparison of injection molding technologies for the production of micro-optical devices. Procedia Eng 69:1296-1305. https://doi.org/10.1016/j. proeng.2014.03.122

2. Young W-B (2005) Effect of process parameters on injection compression molding of pickup lens. Appl Math Model 29(10):955-971. https://doi.org/10.1016/j.apm.2005.02.004

3. J-q Li, D-q Li, Z-y Guo, H-y Lv (2007) Single gate optimization for plastic injection mold. J Zhejiang Univ-Sci A 8(7):1077-1083. https://doi.org/10.1631/jzus.2007.A1077

4. Lee YB, Kwon TH (2001) Modeling and numerical simulation of residual stresses and birefringence in injection molded centergated disks. J Mater Process Technol 111(1):214-218. https://doi. org/10.1016/S0924-0136(01)00524-6

5. Tsai K-M (2013) Runner design to improve quality of plastic optical lens. Int J Adv Manuf Technol 66(1):523-536. https:// doi.org/10.1007/s00170-012-4346-2

6. Barghikar H, Mosaddegh $\mathrm{P}$ (2018) Experimental and simulation study on the optimum of the geometrical quality of bi-convex and bi-concave lenses produced by injection molding process. J Braz Soc Mech Sci Eng 41(1):24. https://doi.org/10.1007/s4043 0-018-1530-9

7. Lu X, Khim Lau Soo (2001) A statistical experimental study of the injection molding of optical lenses. J Mater Process Technol 113(1):189-195. https://doi.org/10.1016/S0924-0136(01)00606 $-9$

8. Tsai K-M, Hsieh C-Y, Lo W-C (2009) A study of the effects of process parameters for injection molding on surface quality of optical lenses. J Mater Process Technol 209(7):3469-3477. https ://doi.org/10.1016/j.jmatprotec.2008.08.006

9. Spina R, Walach P, Schild J, Hopmann C (2012) Analysis of lens manufacturing with injection molding. Int J Precis Eng Manuf 13(11):2087-2095. https://doi.org/10.1007/s12541-012-0276-z

10. Tsai K-M, Lan J-K (2015) Correlation between runner pressure and cavity pressure within injection mold. Int J Adv Manuf Technol 79(1):273-284. https://doi.org/10.1007/s00170-014-6776-5

11. Barghikar H, Mosadegh P, Ranjbar M, Masoumi M (2017) Investigation and simulation of geometric and optical quality for biconvex lens produced by injection molding process. Modares Mech Eng 17(12):21-32

12. 2015 Autodesk I (2016) Autodesk Moldflow Insight/Synergy 2016

13. Bäumer S (2010) Handbook of plastic optics. WILEY-VCH Verlag $\mathrm{GmbH} \&$ Co. KGaA, Weinheim, Federal Republic of Germany

14. Cellere A, Lucchetta G (2010) Identification of crims model parameters for warpage prediction in injection moulding simulation. IntJ Mater Form 3(1):37-40. https://doi.org/10.1007/ s12289-010-0701-8

15. Namdari N, Mosaddegh $P$ (2019) Experimental and simulation studies on the mold replicability in the thermoforming process. Journal of Polymer Engineering, vol 0. https://doi.org/10.1515/ polyeng-2018-0016

16. Singapore SC (2007) Sumipex (Acrilic Molding Resin). Singapore

17. Kazmer DO, Velusamy S, Westerdale S, Johnston S, Gao RX (2010) A comparison of seven filling to packing switchover methods for injection molding. Polym Eng Sci 50(10):2031-2043. https:// doi.org/10.1002/pen.21731

18. Pramujati B, Dubay R, Samaan C (2006) Cavity pressure control during cooling in plastic injection molding. Adv Polym Technol 25(3):170-181. https://doi.org/10.1002/adv.20068

19. Zhou X, Zhang Y, Mao T, Zhou H (2017) Monitoring and dynamic control of quality stability for injection molding process. J Mater Process Technol 249:358-366. https://doi.org/10.1016/j.jmatp rotec.2017.05.038

20. Osswald TA, Menges G (2012) Material science of polymers for engineers. In: Material science of polymers for engineers (third edition). Hanser, pp I-XIX. https://doi.org/10.3139/9781569905 241.fm

21. Farotti E, Natalini M (2018) Influence of process parameters on mechanical properties of polypropylene polymer: a first study. Procedia Struct Integr 8:256-264. https://doi.org/10.1016/j.prost r.2017.12.027

Publisher's Note Springer Nature remains neutral with regard to jurisdictional claims in published maps and institutional affiliations. 